\title{
Laser induced fluorescence study on the growth of maize plants
}

\author{
Marius Hedimbi ${ }^{1}$, Shyam Singh ${ }^{2^{*}}$, A. Kent ${ }^{2}$ \\ ${ }^{1}$ Department of Biological Sciences, University of Namibia, Windhoek, Namibia; \\ *Corresponding Author: ssingh@unam.na \\ ${ }^{2}$ Department of Physics, University of Namibia, Windhoek, Namibia
}

Received 23 March 2012; revised 20 April 2012; accepted 7 May 2012

\begin{abstract}
The laser induced fluorescence (LIF) spectra from plants give accurate information on the influences of ultraviolet $A$ (UV-A) and ultraviolet $B$ (UV-B) radiation on the growth of maize plants. In this paper, a thorough LIF study has been done on maize plants grown under controlled conditions. The maize (Zea mays) seeds were planted and exposed to UV-A and UV-B radiation from 0 to10 hours. The decrease in the ratios of peaks of LIF confirm a decrease in the height, diameter of stem, number of leaves in the plants exposed to UV-B and UV-A with the increase in the time of exposure.
\end{abstract}

Keywords: UV-A Radiation; UV-B Radiation; Zea Mays; LIF

\section{INTRODUCTION}

Stratospheric ozone depletion has caused an increase in the amount of ultraviolet-A (UV-A) and ultraviolet-B (UV-B) radiation reaching the earth's surface (Gao et al., 2004). It is suggested that the maximal ozone depletion and peak UV-B levels will occur during the next decade, with a return to pre-1980 levels of stratospheric ozone and UV-B by the middle of this century [1,2]. UV-A radiation has a wavelength range of $320-440 \mathrm{~nm}$ and UV-B has a wavelength range of $280-320 \mathrm{~nm}$. Since UV-B has a shorter wavelength than UV-A, it is the most damaging ultraviolet radiation [2]. The most important parameter for global irradiance at the surface of the earth is solar elevation above the horizon. The spectral alteration in the UV-B range is mainly caused by ozone layer through which solar radiation must pass [3]. Since cloudiness is a very decisive factor for global irradiance, it is difficult to define general criteria for its influence; however the small contribution of transmitted UV-B cannot be neglected since the photochemical and dam- aging effects of plants increase exponentially with increasing wavelength [3].

Remote sensing techniques are widely used these days to study plants. In remote sensing applications, laserinduced fluorescence (LIF) is a powerful technique, which can be used for early remote sensing of stress conditions in plants $[4,5]$. LIF is an active sensing technique capable of capturing immediate and specific indications of changes in plant physiology and metabolism as they relate to the concentration and photosynthetic activity of the plant pigment. There are several advantages in the use of pulsed UV lasers as excitation sources. For example, the use of this excitation spectral range is recommended by international eye-safe regulation in remote sensing. Another advantage is that the powerful and reliable laser sources are available in the whole spectral range of UV [5]. The continuous fluorescence can be obtained from a high repetition rate pulsed excitation. Furthermore, the fluorescence emission spectra may have range as wide as possible and hence the increasing information contents in the LIF technique [4,5]. UV LIF emission of green plants has become of great interest with respect to application of remote fluorescence light detection and ranging (LIDAR) techniques for screening the state of health of terrestrial vegetation $[4,6]$. Green leaves excited by UV light emit red fluorescence between 650 and $800 \mathrm{~nm}$ (known as chlorophyll fluorescence) and afluorescence emission in the blue-green spectral region $[5,6]$.

Plant damage caused by environmental changes can be studied using LIF technique. Mineuchi et al. [7] used LIF technique to study the effects of UV-B radiation on peanut leaves. They evaluated the vitality decrease of leaves by measuring the change in a specific fluorescence peak ratio. They found that an early detection and evaluation of UV-B stress could be possible by applying the method of remote sensing. Takeuchi et al. [8] investigated leaf samples irradiated by UV-B and found that at two wavelengths, namely 685 and $735 \mathrm{~nm}$, the LIF lifetimes became shorter during UV-B irradiation. They established a 
relationship between the lifetimes and plant's activities under UV-B irradiation.

Maize is one of the most important staple foods in the world. Therefore the study of maize seedlings to stimulated UV-A and UV-B light under laboratory conditions is very important for assessment of the responses of maize plants to a stress factor in the fields [9]. The effects of UV-A and UV-B on the growth of maize seedlings have been reported by several researchers [3,9-11]. Several investigators have demonstrated that the effect of UV-B radiation enhancement on plants includes reducetion in grain yield, alteration in species competition, susceptibility to diseases and changes in plant structure and pigmentation [2,9]. The enhanced UV radiation can cause deleterious effects to DNA, the photosynthetic system and other target molecules. Some effects on photosynthesis may also include alteration in light penetration into the leaf, changes in chlorophyll and stomata density, and reduction in leaf area [2,12]. The objective of this study was to evaluate the effects of UV-A and UV-B radiation on the growth of maize seedling using laser induced fluorescence (LIF) technique. This may be used to get an overview of what happens when maize plants are growing in UV regions under field conditions, and help find measures on how to protect crops from increasing UV-A and UV-B radiation [9].

\section{MATERIALS AND METHODS}

\subsection{Growing and Exposure of Maize Seedlings to UV Radiation}

Fifteen pots were filled with sandy soil. The depth of the seeds in the soil was kept at $1 \mathrm{~cm}$ and the pots were left to stand under normal (white) light during the day and under a dark mode during night time by switching the lights off. Each pot contained 3 seeds. The pots were watered with $100 \mathrm{ml}$ of water every 3rd day for 2 weeks. The seedlings were divided into two groups. One group was exposed to UV-A (Philips, F40T, 12/B1, Actinic) and another group was exposed to UV-B (Philips, TL. 40W/12RS, J2) lamb lights. The exposure to UV-A and UV-B radiation was given for up to10 hours at two hour intervals. Each experiment was done using three replicates. The protocol used in this study was previously reported by Hedimbi et al. [9].

\subsection{Laser Induced Fluorescence Spectrum}

After the exposure of the maize seedlings (every 2 hours), the emission spectrum of the third leaf from the bottom, side of each maize seedling excited by $663 \mathrm{~nm}$ was obtained, using Ava Light-D(H)S Deuterium-Halogen light sources which is connected to Ava Spec-2048 Fiber Optic Spectrometer and a computer for displaying the results in a graph format.

\section{RESULTS AND DISCUSSIONS}

The LIF spectrum was taken from the bottom of third leaf of each plant grown under normal conditions and under stress of UV-A and UV-B exposure and we have shown the spectrum taken for the third leaf in the Figures 1-10. For each plant, we have shown the kind of stress given to the plant and time of stress. Figures 1-5 show LIF spectrum for UV-A stress given to plants for 2 hours (Figure 1), 4 hours (Figure 2), 6 hours (Figure 3), 8 hours (Figure 4) and 10 hours (Figure 5). Figures 610 shows LIF spectrum of plants exposed to UV-B radiation for 2 hours (Figure 6), 4 hours (Figure 7), 6 hours (Figure 8), 8 hours (Figure 9) and 10 hours (Figure 10). Each spectrum has four peaks at $410 \mathrm{~nm}, 450 \mathrm{~nm}, 560$ $\mathrm{nm}$, and $600 \mathrm{~nm}$. The intensity ratios of these peaks as F410/F450, F410/F560, and F560/F600 corresponding to blue to green, blue to red, and chlorophyll fluorescence were calculated and analyzed (Tables 1 and 2). It was found that the ratio F560/F600 decreased due to the photosynthesis activity whereas the ratio of F410/F450 was found to have decreased with the increase of UV-A and UV-B radiation but the ratio of F410/F560 was found to be increased with the increase of UV-A and UV-B radiation (Tables 1 and 2). Furthermore, it was found that UV-B was more effective than UV-A in reducing photosynthetic activity of maize plants as shown in Tables 1 and 2.

The continuous growth of plants indicates that they can tolerate or adapt to UV radiation and can survive. The epidermis usually protects the inner leaf with high

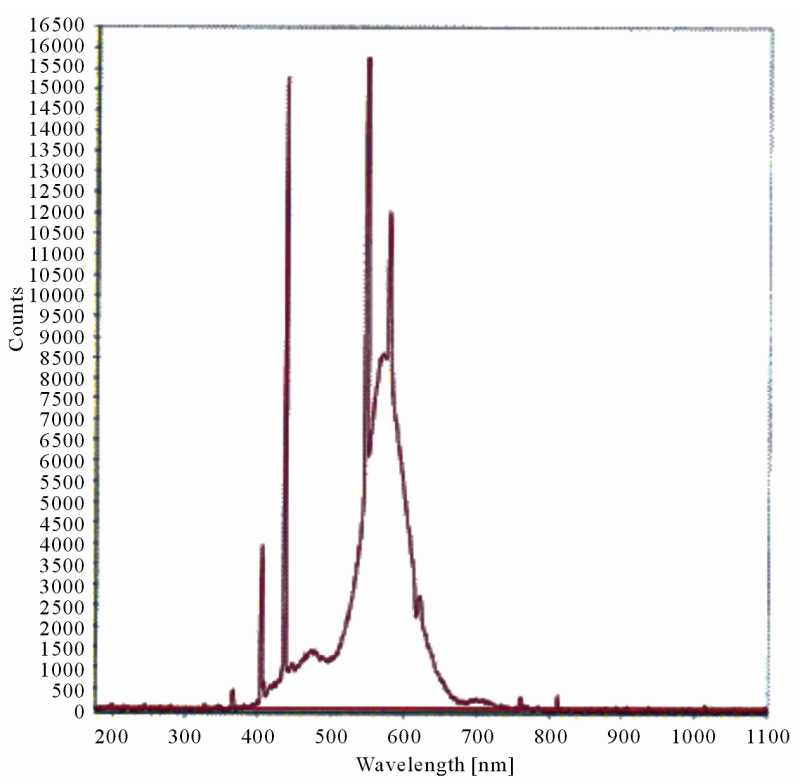

Figure 1. LIF spectrum of maize leaves exposed to 0 - 10 hours of UV-A radiation. 


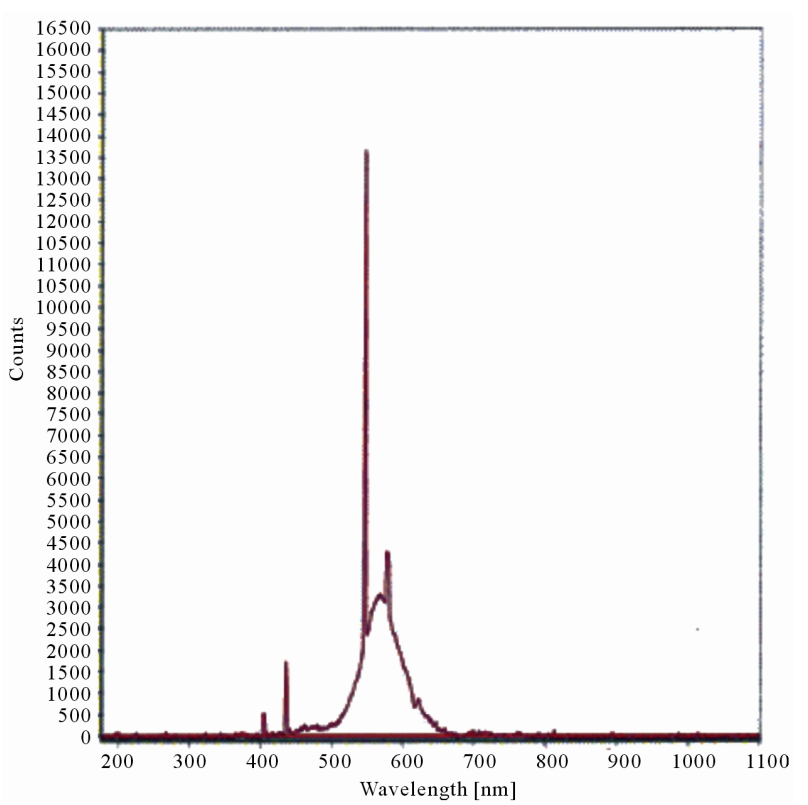

Figure 2. LIF spectrum of maize leaves exposed to 4 hours of UV-A radiation.

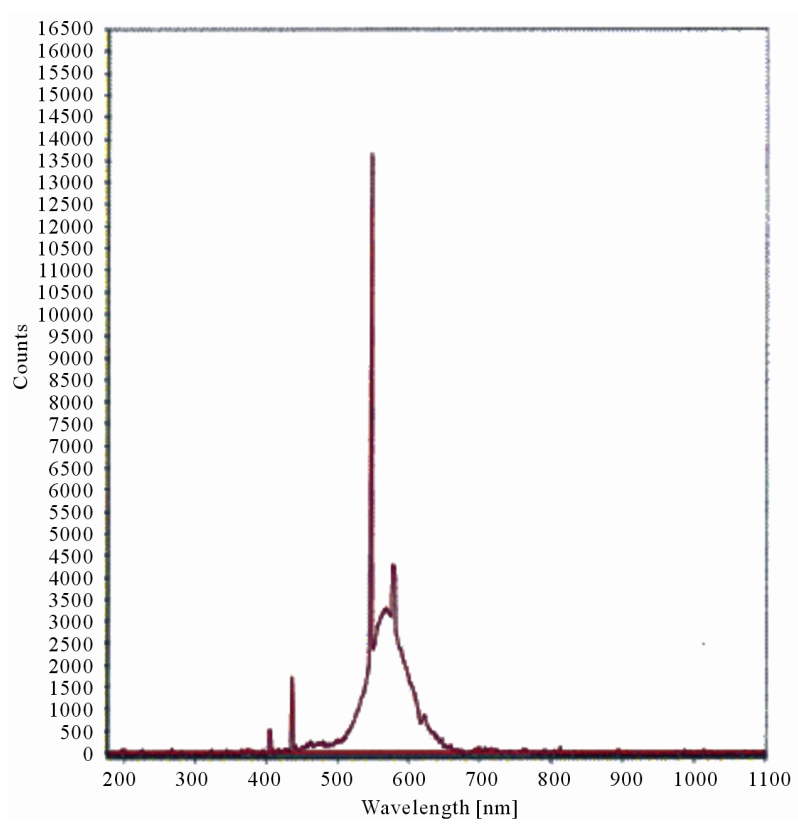

Figure 3. LIF spectrum of maize leaves exposed to 6 hours of UV-A radiation.

concentrations of flavonoids and anthocyanins, which absorb the UV radiation safely. The UV treatment is affected by photosynthetically active radiation (PAR) levels $[13,14]$. Whether the presence or absence of activated photomorphogenic, photosynthetic and photoprotective systems during the UV treatment affect plant sensitivity to UV radiation or not has not been investigated so far. For example, the possible role of photosynthetic process and of xanthophyll cycle activated by wavelengths $>500$

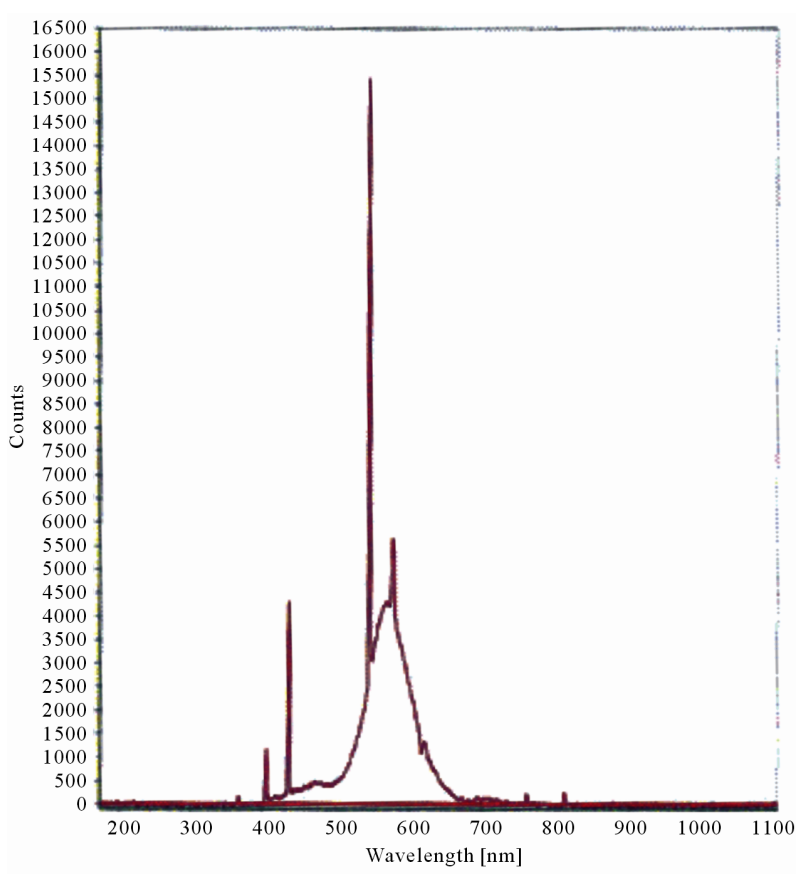

Figure 4. LIF spectrum of maize leaves exposed to 8 hours of UV-A radiation.

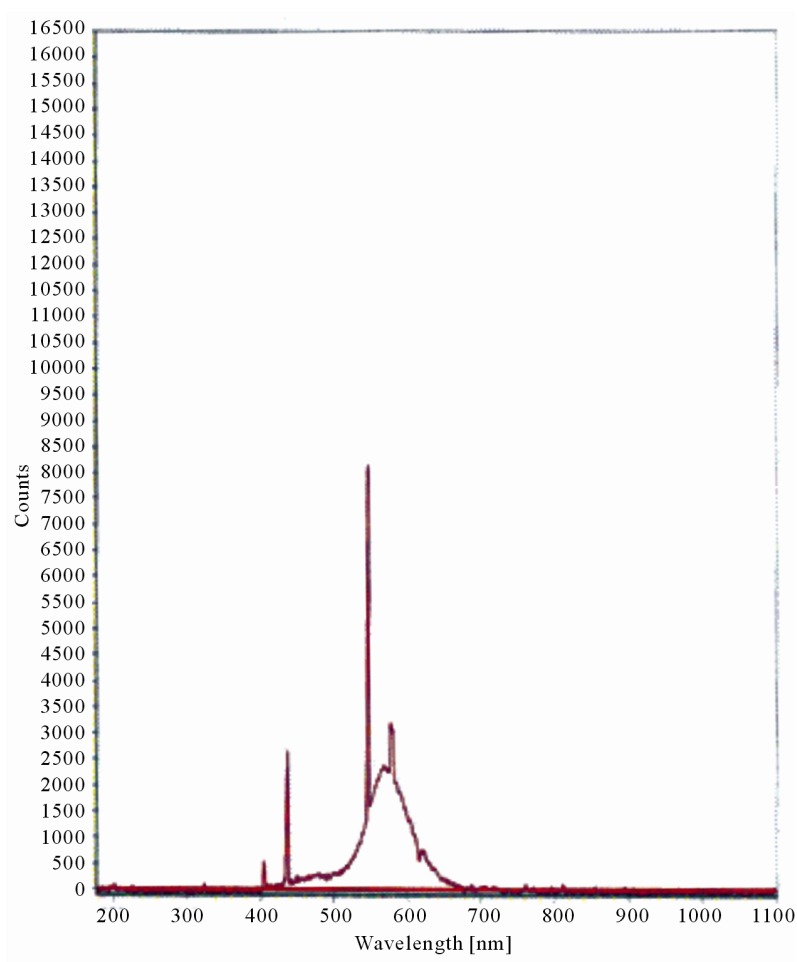

Figure 5. LIF spectrum of maize leaves exposed to 10 hours of UV-A radiation.

nm has not been determined because UV irradiation is always been given in the presence of PAR [11].

UV-B radiation causes a multitude of physiological and biochemical changes in plants, including inhibition 


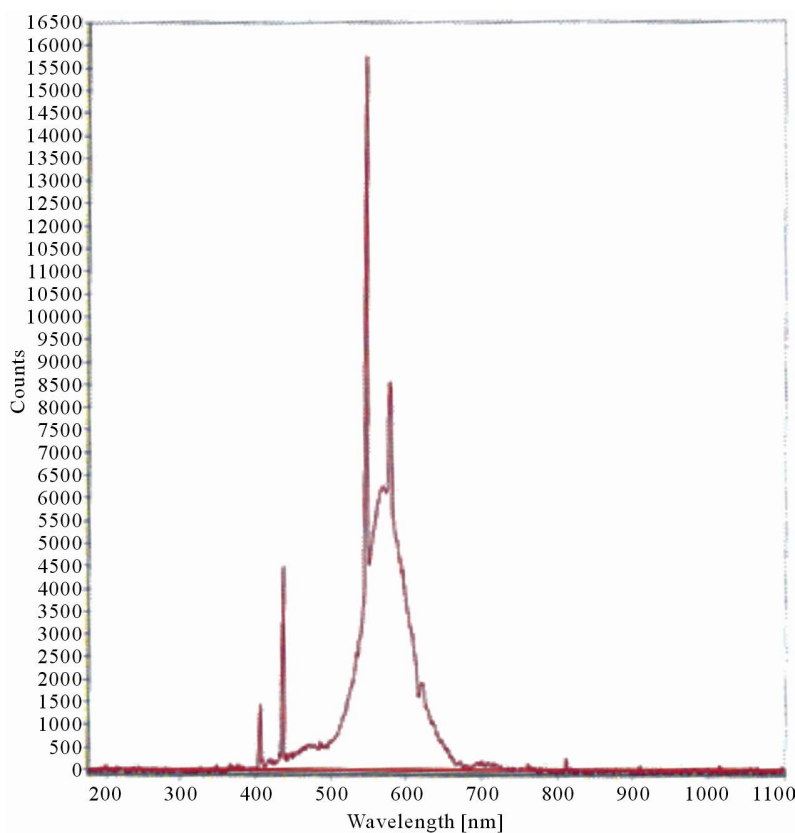

Figure 6. LIF spectrum of maize leaves exposed to 2 hours of UV-B radiation.

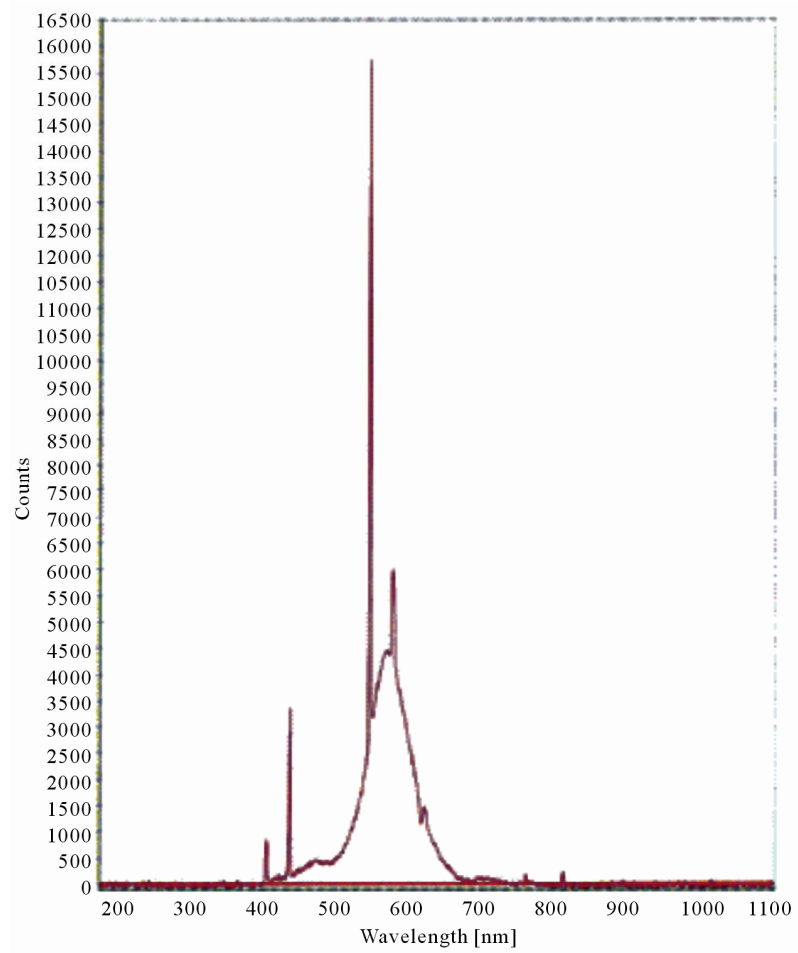

Figure 7. LIF spectrum of maize leaves exposed to 4 hours of UV-B radiation.

of photosynthesis $[15,16]$. This inhibition is due to reduced levels of chlorophyll (Chl), chloroplast proteins such as Rubisco (ribulose-1,5-bisphosphate carboxylase/ oxygenase) and LHCII (light-harvesting chlorophyll a/b-binding protein of photosystem II) $[16,17]$, and pho-

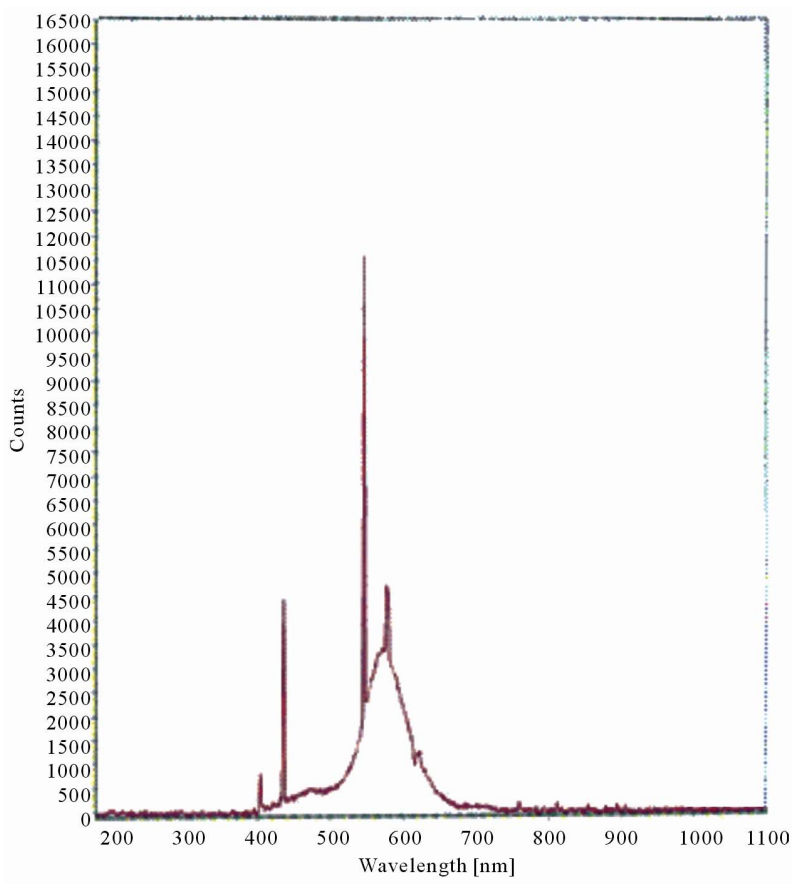

Figure 8. LIF spectrum of maize leaves exposed to 6 hours of UV-B radiation.

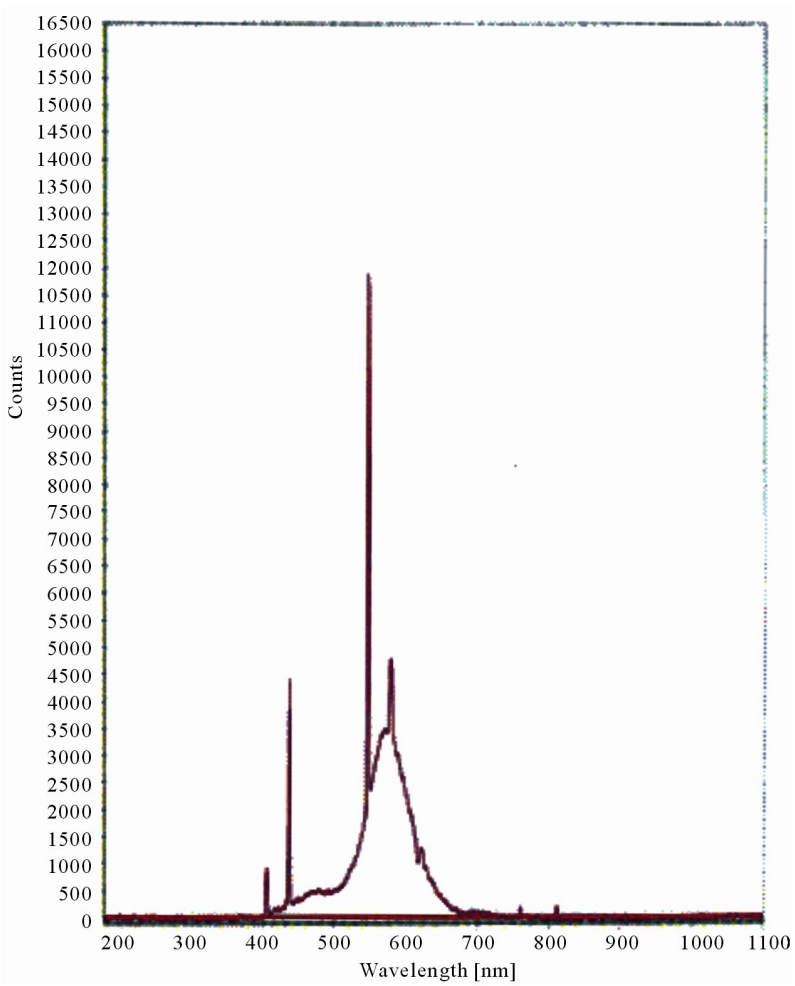

Figure 9. LIF spectrum of maize leaves exposed to 8 hours of UV-B radiation.

tosynthesis-related gene expression [16,18]. Allen et al. [19] reported that loss of Rubisco is a primary factor in UV-B inhibition of photosynthesis in oilseed rape. Further, 


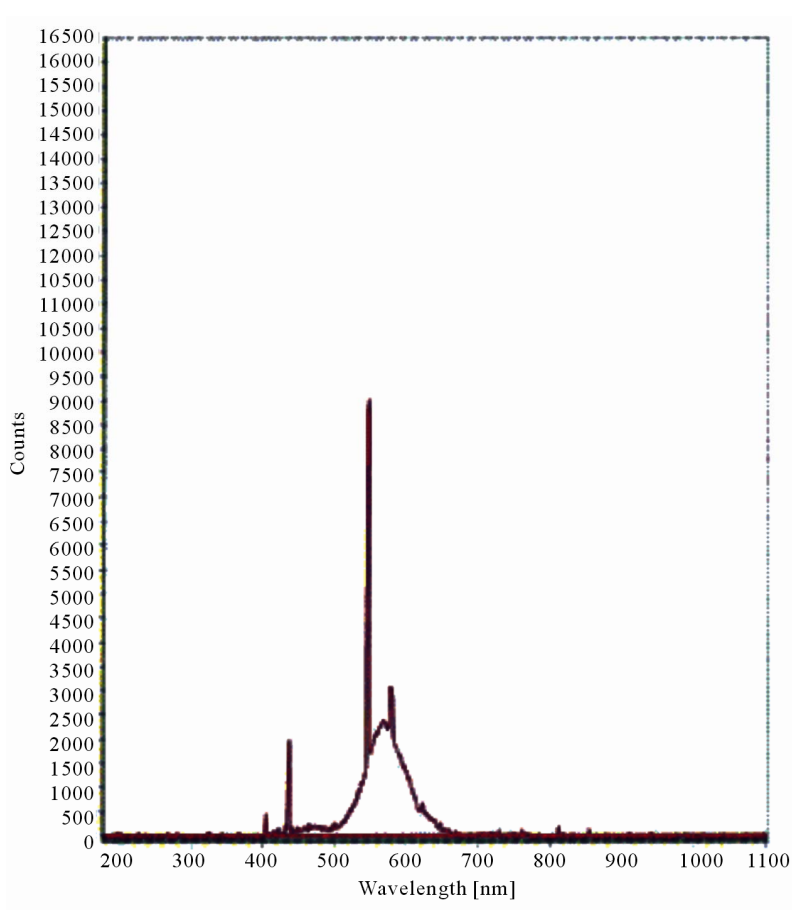

Figure 10. LIF spectrum of maize leaves exposed to 10 hours of UV-B radiation.

Table 1. The fluorescence intensity ratios of maize leaves exposed to UV-A with their respective standard errors of three replicates.

\begin{tabular}{cccc}
\hline UV-A (hours) & F410/F450 & F450/F560 & F560/F600 \\
\hline $\mathbf{0}$ & $0.4 \pm 0.0$ & $0.2 \pm 0.0$ & $2.9 \pm 0.1$ \\
$\mathbf{2}$ & $0.3 \pm 0.0$ & $0.2 \pm 0.1$ & $2.7 \pm 0.1$ \\
$\mathbf{4}$ & $0.3 \pm 0.0$ & $0.3 \pm 0.0$ & $2.1 \pm 0.0$ \\
$\mathbf{6}$ & $0.3 \pm 0.0$ & $0.3 \pm 0.2$ & $1.7 \pm 0.1$ \\
$\mathbf{8}$ & $0.3 \pm 0.0$ & $0.6 \pm 0.0$ & $1.7 \pm 0.1$ \\
$\mathbf{1 0}$ & $0.2 \pm 0.0$ & $0.4 \pm 0.1$ & $1.6 \pm 0.1$ \\
\hline
\end{tabular}

Table 2. The fluorescence intensity ratios of maize leaves exposed to UV-B with their respective standard errors of three replicates.

\begin{tabular}{cccc}
\hline UV-B (hours) & F410/F450 & F450/F560 & F560/F600 \\
\hline $\mathbf{0}$ & $0.4 \pm 0.0$ & $0.3 \pm 0.1$ & $2.5 \pm 0.1$ \\
$\mathbf{2}$ & $0.3 \pm 0.5$ & $0.3 \pm 0.1$ & $2.2 \pm 0.3$ \\
$\mathbf{4}$ & $0.3 \pm 0.0$ & $0.4 \pm 0.8$ & $2.1 \pm 0.1$ \\
$\mathbf{6}$ & $0.3 \pm 0.0$ & $0.4 \pm 0.0$ & $2.0 \pm 0.4$ \\
$\mathbf{8}$ & $0.2 \pm 0.0$ & $0.4 \pm 0.0$ & $1.4 \pm 0.2$ \\
$\mathbf{1 0}$ & $0.2 \pm 0.0$ & $0.4 \pm 0.1$ & $1.1 \pm 0.5$ \\
\hline
\end{tabular}

it was apparent that the UV-B induced reduction in Rubisco was greater in UV-sensitive, than in UV-resistant strains [16].

It has been reported that, in chloroplasts under illumination, the large subunit (LSU) of Rubisco is directly fragmented into two polypeptides by reactive oxygen species (ROS) [20,21]. Other authors have demonstrated that UV-B generated ROS induce photodamage to Rubisco [22], and that ROS cause proteolytic degradation of the LSU [23]. Thus, the generation of ROS is thought to be involved in UV-B induced degradation of Rubisco in rice. John et al. [24] reported that, in Arabidopsis, exposure to UV-B radiation induces expression of senescence-associated genes (SAGs), including SAG12, which encodes a cysteine protease [16,25]. This result suggests that the formation of some kind of protease may also be involved in the enhancement of Rubisco degradation in plants [16].

Singh et al. [10] studied the effects of UV-A radiation on the growth of maize plants and their fluorescence spectra. The emission spectra of the second leaf from the bottom side of each maize plant excited by $337 \mathrm{~nm}$ were obtained using spex 1680, 0.22 m double monochromator known as spexfluorolog made in USA. The spectra consisted of two peak bands in the blue-green region at $435 \mathrm{~nm}$ (F435) and $525 \mathrm{~nm}$ (F525) respectively and two peak bands in the red region at $684 \mathrm{~nm}$ (F684) and 740 nm (F740) respectively. The ratios of these peaks as (F435/F525), (F435/F684) and (F684/F740) were calculated in each case. The ratio of blue to red (F435/F684) and chlorophyll fluorescence (F684/F740) ratio were found be decreased. This might be due to the fact that the intensity of red peaks was increased due to reabsorption of light when the plants were treated with UV-A, and hence the ratios (F435/F684) and (F684/F740) were reduced $[3,5,10]$.

LIF obtained from intact leaves under different conditions and their quantitative relation to stress detection has been discussed in detail by Theisen [26]. Fluorescence of plant tissues is considered a serious problem in immuno fluorescence microscopy investigation of signified tissues and tissues with vacuolar deposits of phenolic compounds and in some cases it has been eliminated by the use of strong reducing substances [3,5]. Oxidized chlorophylls that emit at $540 \mathrm{~nm}$ are released to vacuoles from chloroplasts [3,5]. Broglia [26] found a decrease of laser induced green fluorescence and increase of chlorophyll fluorescence in Vicia faba when epidermal tissue had been removed. This shows that the epidermis is both an important protection against UV radiation and a possible topological source of green fluorescence [3,5].

There are two potential primary mechanisms involved in UVB-induced physiological and biochemical damage. DNA lesions, such as cyclobutane pyrimidine dimer 
(CPD) and pyrimidine (6-4) pyrimidone photoproducts [(6-4) photoproduts], interfere with DNA replication and transcription $[16,27]$. The second mechanism is through modification of proteins by photo-oxidation, or by reactive oxygen species (ROS) and free radicals produced during photosensitization [16,22,27]. These modifications include cross-linking, aggregation, denaturation and degradation [16,27].

Gao et al. [2] investigated the effects of supplementary UV-B radiation on the growth, yield and seed qualities of maize under field conditions. Increased UV-B radiation caused a significant reduction in dry matter and yield, and affected seed quality as follows: protein, sugar and starch levels decreased, whereas lysine levels increased. Taken together, the results of this study suggest that the enhanced solar UV-B radiation as predicted by atmospheric models will result in reduction of growth and yield of maize crops in the future. This has been confirmed from this study that the enhanced UV-A and UV-B radiation causes a significant reduction in the growth of maize plants and hence in the yield in turn. However, to have proper protection, the excessive exposure of both UV-A and UV-B should be avoided to have better growth of yield. Also, it has been observed that maize can sustain certain level of UV-A, but excessive exposure will be dangerous to plants whereas exposure of UV-B of any level is harmful to plants.

\section{ACKNOWLEDGEMENTS}

We are grateful to the department of Physics and the department of Biological Sciences at the University of Namibia for laboratory space and equipment.

\section{REFERENCES}

[1] Day, T.A. and Neale, P.J. (2002) Effects of UV-B radiation on terrestrial and aquatic primary producers. Annual Review of Ecology and Systematics, 33, 371-396. doi:10.1146/annurev.ecolsys.33.010802.150434

[2] Gao, W., Zeng, Y., Slusser, J.R., Heisle, G.M., Grant, R.H., $\mathrm{Xu}, \mathrm{J}$. and He, D. (2004) Effects of supplementary ultraviolet-B radiance on maize yields and qualities. Photochemistry and Photobiology, 80, 127-131. doi:10.1562/2004-05-03-RA-156.1

[3] Kent, A. and Singh, S. (2008) Effects of UV-A and UV-B radiation on vegetation. Atti della Fondazione Giorgio Ronchi, 3, 353-388.

[4] Chappelle, E.W. (1991) Identification of the pigment responsible for the blue fluorescence band in the laser induced fluorescence (LIF) spectra of green plants and potential use of this band in remotely estimation rates of photosynthesis. Remote Sensing of Environment, 36, 213218. doi:10.1016/0034-4257(91)90058-E

[5] Kent, A. and Singh, S. (2006) Lacer induced fluorescence on vegetative plants. Atti della Fondazione Giorgio Ron- chi, 6, 687-724.

[6] Lichtenhatler, H.K. (1992) The nature of the different laser-induced fluorescence signatures of plants. EARSel Advances in Remote Sensing, 1, 20-32.

[7] Mineuchi, K., Takahashi, K. and Tatsumoto, H. (2001) Effects of UV-B radiation on laser-induced fluorescence spectra in crop leaves. Environmental Technology, 22, 151-155. doi:10.1080/09593332208618292

[8] Takeuchi, A., Saito, Y., Nakazawa, Y., Kawahara T.D. and Nomura A. (2002) Detection of in vivo plant leaves damage process irradiated by UV-B using time-resolved laserinduced fluorescence method. Review of Laser Engineering, 30, 666-671. doi:10.2184/lsj.30.666

[9] Hedimbi, M., Naikaku, N. and Singh, S. (2012) Effects of stimulated UV radiation on the growth of maize seedlings. Journal of Research in Plant Sciences, 1, 93-98.

[10] Singh, S., Dube, A. and Gupta, P.K. (1998) Fluorescence study of maize irradiated by UV-A. Pure and Applied Optics, 7, 39-42.

[11] Singh, S. (2000) Effects of UV-B on the growth of maize plants using fluorescence parameters. Asian Journal of Physics, 9, 861.

[12] Sullivan, J.H. and Rozema, J. (1999) UV-B effects on terrestrial plant growth and photosynthesis. In: Rozema, J., Ed., Stratospheric Ozone Depletion: The Effects of Enhanced UV-B Radiation on Terrestrial Ecosystems, Backhays Publishers, Leiden, 39-57.

[13] Adamse, P. (1994) Melioration of UV-B damage under high irradiance II: Role of blue light photoreceptors. Photochemistry Photobiology, 60, 110-115. doi:10.1111/j.1751-1097.1994.tb05075.x

[14] Giannini, A. (1996) The use of UV radiation to control the architecture of salvia splendens plants I: Effects on plant growth, water relations and gas exchange. Photochemistry Photobiology, 64, 123-130. doi:10.1111/j.1751-1097.1996.tb02431.x

[15] Bornman, J.F. and Teramura, A.H. (1993) Effects of ultraviolet-B radiation on terrestrial plants. In: Young, A,R., Bjorn, L.O., Moan, J. and Nultsch, W., Eds., Environmental UV Photobiology, Plenum Press, New York, 427471.

[16] Hidema, J. and Kumagi, T. (2006). Sensitivity of rice to ultraviolet-B radiation. Annals of Botany, 97, 933-942. doi:10.1093/aob/mcl044

[17] Strid, A., Chow, W.S. and Anderson, J.M. (1990) Effects of supplementary ultraviolet-B radiation on photosynthesis in Pisum sativum. Biochimica et Biophysica Acta, 1020, 260-268. doi:10.1016/0005-2728(90)90156-X

[18] Strid, A, Chow, W.S. and Anderson, J.M. (1996) Temperature-dependency of changes in the relaxation of electrochromic shifts, of chlorophyll fluorescence, and in the levels of mRNA transcripts in detached leaves from Pisumsativum exposed to supplementary UV-B radiation. Plant Science, 115, 199-206. doi:10.1016/0168-9452(96)04346-4

[19] Allen, D.J., Mckee, I.F., Farage, P.K. and Baker, N.R. (1997) Analysis of limitations to $\mathrm{CO}_{2}$ assimilation on exposure of leaves of two Brassica napus cultivars to UV-B. 
Plant, Cell and Environment, 20, 633-640. doi:10.1111/j.1365-3040.1997.00093.x

[20] Ishida, H., Makino, A. and Mae, T. (1999) Fragmentation of the large subunit of ribulose-1,5-bisphosphate carboxylase by reactive oxygen species occurs near Gly-329. Journal of Biological Chemistry, 274, 5222-5226. doi:10.1074/jbc.274.8.5222

[21] Ishida, H., Shimizu, S., Makino, A. and Mae, T. (1998) Light-dependent fragmentation of the large subunit of ribulose-1,5-bisphosphate carboxylase/oxygenase in chloroplasts isolated from wheat leaves. Planta, 204, 305-309. doi:10.1007/s004250050260

[22] Caldwell, C.R. (1993) Ultraviolet-induced photodegradation of cucumber (Cucumissativus L.) microsomal and soluble protein tryptophanyl residues in vitro. Plant Physiology, 101, 947-953.

[23] Desimone, M., Henke, A. and Wagner, E. (1996) Oxidative stress induces partial degradation of the large subunit of ribulose-1,5-bisphosphate carboxylase/oxygenase in isolated chloroplasts of barley. Plant Physiology, 111, 789-796.

[24] John, C.F., Morris, K., Jordan, B.R., Thomas, B. and A-H-Mackerness, S. (2001) Ultraviolet-B exposure leads to up-regulation of senescence associated genes in Arabidopsis thaliana. Journal of Experimental Botany, 52, 1367-1373. doi:10.1093/jexbot/52.359.1367

[25] Noh, Y.S. and Amasino R.M. (1999) Regulation of developmental senescence is conserved between Arabidopsis and Brassica napus. Plant Molecular Biology, 41, 195-206. doi:10.1023/A:1006389803990

[26] Broglia, M. (1993) Blue-green laser-induced fluorescence from intact leave: Actinic light sensitivity and subcellular origins. Applied Optics, 32, 334-338. doi:10.1364/AO.32.000334

[27] Britt, A.B. (1996) DNA damage and repair in plants. Annual Review of Plant Physiology and Plant Molecular Biology, 47, 75-100. doi:10.1146/annurev.arplant.47.1.75 